his illness, he was out of work, and fared very badly. Shortly before his attack, he had removea into a damp house.

The illness began on November 9th, at 2 A.M., he having gone to bed perfectly well. He was then taken with repeated rigors, and with pain at the back of the right side. He had walked during the day a long distance in search of work, had got his feet wet, and had not changed his shoes. He suffered much from cough, but had no expectoration. On admission, he presented the physical signs of pneumonia, involving the entire right lower lobe. He had some cough, but no expectoration, and complained of pain at the back of the right side on sitting upright. His aspect, as he lay, was that of perfect health. He complained of no discomfort, and had even been passed over in the visit of the preceding day, as being affected only with a trivial ailment. His tongue presented a thin white fur. The only evidence of anything important being amiss was, that he was manifestly much depressed when he sat up.

Throughout his illness, his chief symptoms underwent no alteration; he was alert and cheerful, and took his food with appetite. On the fourth day of treatment, he was found sitting up and writing a letter. His cough was easily restrained by morphine linctus. He took no medicine except the linctus mentioned above. He had two turpentine stupes to his side, and a fomentation. He was put on milk diet.

The physical signs of the disease remained present for an unusually long period. The dulness had not disappeared until December 1st, the twentythird day of the disease; but the crepitatio redux appeared on the ninth day.

The temperature in the axilla was $102.6^{\circ}$ on the fifth day of the disease. On the sixth day, it rose to $103^{\circ}$, and in the evening to $104^{\circ}$. On the seventh day, it was still at $104^{\circ}$; but, in the evening, had fallen to $101.8^{\circ}$. The day following, it was $100.8^{\circ}$ in the morning, and $99^{\circ}$ in the evening. Thence it continued at the normal standard.

The pulse, which was 112 on the fifth day, was 84 on the eighth. The respiration varied between 29 and 31 up to the eighth day, when it was 20 , but afterwards rose to 26 and 24 . The urine was about forty ounces, specific gravity 1020, without albumen. The chlorides were absent.

Patrons of Medical Heresies. The doctors say that it is the parsons who are the chief support of homœopathy, hydropathy, and all the medical heresies. The clergyman's wife used to be a great ally of the village doctor, and was generally content to act under orders, and fill the place of an intelligent assistant. In those days, the clergyman was generally "in his study," unless he was out with the hounds or "gone a-fishing." But things are changed nowa-days; men see more of their flocks; they soon find that the body needs care as well as the soul-that little is to be done with the one unless you are content to try to do something for the other. So they take doctoring in hand, and are naturally less manageable than their "better halves." The BRITISH Medical Journal calls them "the chief promoters of quackery in this country", and notices the curious fact that in France (where, also, public opinion is strongly in favour of free trade in physic) it is the sisterhoods who are the chief enemies of the regular practitioner. A French medical paper complains that in some rural districts the doctor's occupation is gone, owing to the concurrence effréné of the local religieuses. (Pall Mall Gazette.)

\section{original Crommaniations.}

\section{RECURRENT MILIARIA AFTER SCARLET FEVER.}

By Thomas Balman, M.D., Liverpool.

[Read before the Liverpool Medical Socicty, Nov. 16, 1865.]

THe following case recently came under my observation at the Dispensary for Diseases of the Skin, and presents some peculiarities worth notice.

R. F., aged 25, collector for a benefit club in this town, a thin and somewhat delicate-looking man, applied to the dispensary on October 9th. He stated that he was very well up to October 4th, 1862, when he was seized with a bad attack of scarlet fever, from the effects of which he was laid up for nearly a month. He had symptoms of dropsy, and otherwise felt very weak and ill, for some time after the fever had left. him. On December 24th, he had a slight shivering. fit, followed by heat of skin, sickness, pain in the limbs, great depression of spirits, and general malaise. Next day (the second of attack), he perceived that his face was slightly swollen, and that his eyes felt stiff on opening them in the morning. These symptoms were accompanied with a peculiar eruption, consisting of small white pimples, globular in shape, and filled with matter. There were also similar ones, though not so numerous, on his breast, neck, and backs of his hands and fingers. The eruption on the body was often preceded or attended by a distinct rash, which often felt itchy and uncomfortabie, but not painful. The pustules usually terminated in eight or nine days, by a scurfy desquamation of the cuticle on the face, whilst the palms of the hands, and sometimes the feet, peeled off in large laminated scales. Most of the symptoms were relieved after the appearance of the eruption; but the feeling of sickness continued for some time afterwards. In 1863 , he had four separate attacks of precisely the same kind; the first in March, and the last in the early part of the December following.

In 1864, he had also several attacks, though not quite of the same severity, lasting sometimes only three or four days. This year, he has already (Nov. 1865) had five; occurring in the following orderJanuary, March, May, September, and October. He knows when he is to be ill by the symptoms described and the slight swelling of the face; which, he says, uniformly precedes the eruption. He did not notice that he perspired more freely at these periods than at any other time. He took once, by his father's wish, a potion of Cayenne-pepper and herbs, which brought out the eruption in full force, and made him otherwise much worse. He thinks his attacks may sometimes have come on after exposure to cold, being at the same time much heated and perhaps perspiring freely.

I saw him for the first time on November 7th last, the second day of the eruption, and third from the first commencement of the attack. He was then found to have a hard, quick, but not intermittent pulse; considerable heat of skin; and slight feverish excitement. His tongue was clean, and the papillæ natural. Each cheek was studded, at about its centre, with a group of well marked miliary vesicles, closely packed together, but quite distinct, and filled with a very fluid milky looking pus. On the left side, I counted as many as forty. There were others, more scattered and rather smaller, on other parts of his face, and especially on the chin, where they pre- 
sented, very exactly, that peculiar pearly appearance, so often described by writers who have seen the disease often. Some of the pustules situated on the left side of the face were surrounded by a pink border. Other parts of the face presented no such appearance; but seemed even more pallid than natural. Hence the epithets miliaria rubra and alba which have been used by authors to mark these differences. Both these forms were obvious enough in the progress of the case, and indeed at the same moment of time, as we have just seen; and shows that these distinctions are perfectly unnecessary, being simply different stages of the same eruption. That part of the cheek on which the eruption invariably recurred, and which might be covered by a half-crown piece, was marked by a series of small cup-shaped depressions, such as we see often occurs after confluent small-pox. No such appearances were observable on other parts of the face, where the eruption was always less copious.

A specimen of his urine, on being examined, appeared of a pale straw-colour, moderately acid; had a specific gravity of 1025 ; and contained a considerable quantity of the oxalate of lime crystals.

REMaRKs. The pathognomonic symptoms of miliaria, or miliary fever, as it is generally designated, are so well marked in this case, that it could not well be mistaken by an attentive observer for any other disease. Its peculiarities are : its recurrent character, and fastening itself in so remarkable a way on the face, where it is said to occur so rarely. I may add, also, the absence of any tendency to diaphoresis, which was at one time supposed to be one of its essential attendant symptoms.*

Very different opinions have from time to time been entertained by physicians and dermatologists as to the essential nature of this disease. By some it has been described as a purely idiopathic eruptive fever, depending upon some subtle and unknown poison, similar to scarlatina, measles, or small-pox. Others, on the contrary, looking merely at the anatomical element of the eruption, follow Willan and Bateman, and regard it as merely symptomatic of some previously induced feverish state of body; the grounds upon which they have based this opinion being, that a miliary eruption has been found very frequently to attend some stage of almost every form of fever, and especially when such fevers, as was formerly the case, were treated by keeping persons in a confined room, and subjecting them to a heating regimen; when, as Sir R. Blackmore quaintly expresses it, "patients were packed in blankets, and suffered to remain for days together, drowning in sweats." $\dagger$

* " Of the symptoms said to be concomitant of this eruption, there are none which can be said to be constant and peculiar, but that of sweating. This, indeed, always precedes and accompanies the eruption; and, while the miliary eruption attends many different diseases, it never, however, appears in any of these but after sweating; and, in persons labouring under these diseases, it does not appear if sweating be avoided. It is, therefore, probable that the eruption is the effect of sweating; and that it is the produce of under particular circumstances, in the skin itself. That it depends under particular circumstances, in the skin itself. That it depends
upon particular circumstances of the skin, appears further from hence, that the eruption seldom or never appears upon the face, although it affects the whole body besides; that it comes upon those places especially which are more closely covered; and that it can be brought out upon particular parts by external applications." (Cullen's Works, by Thomson, vol. ii, p. 194.)

+ Among the various circumstances under which the miliaria was formerly excited, the puerperal state appears to have been most frequently the source of it; insomuch, that it was first described as an epidemic among puerperal women. This is sufficiently accounted for by the treatment which was unhappily pursued during the confinement after childbirth, and of which an impressive description is given by Mr. White. "For not only was the mother immediately loaded with bed-clothes, from which she was not allowed to put out even her nose, and supplied with heating liquors from the spout of a tea-pot; but to her room, heated by a crowd of visitors and a fire, all access of air was denied, even through a key-hole. From these
That the prolonged contact of clothes soaked in the acrid perspiration thrown off from the skin in puerperal, rheumatic, and other fevers, should, by its irritating properties alone, sometimes give rise to vesicular eruptions or sudamina, with which the true miliary eruption has unfortunately been confounded, is very probable. But there is abundant evidence, independently of the case I have just mentioned, to show that profuse diaphoresis is by no means necessary for the development of these so-called sudamina. Dr. Ormerod states that, in the epidemic (relapsing or famine fever) which was prevalent in London during the spring of 1847 among the Irish who had newly arrived in London, there was no tendency to profuse perspiration; nevertheless, miliary vesicles or sudamina were exceedingly common in St. Bartholomew's Hospital. (Ormerod : Clinical Observations on Continued Fever at St. Bartholomew's Hospital, London. 1848.)

Bouteille made a note of fourteen hundred cases in which a miliary eruption appeared, although the patients had been treated by a cool and antiphlogistic regimen, and in whom there was no particular tendency to perspiration. Rayer has made similar observations in regard to the epidemic that prevailed in France in 1821. (Hist. de l'Epidémie de Suette Miliare qui a regné en 1821 dans le Department de l'Oise. 8vo. Paris. Vide also Pujol : Mémoire sur le Fière Miliare qui regna en Languedoc durant le Printemps de 1782.)

It is probable that the eruption so often met with in the progress of typhus and other fevers, and which has been represented to be of a miliary character, has been sometimes nothing else but petechial spots or purpura, and that the true miliary eruption is by no means so common as it was at one time supposed to be. Henderson, for example, met with only three instances of the true miliary eruption in 198 cases of typhus; and Douglas (Douglas, Statistical Report on the Edinburgh Epidemic Fever of 1843-4, Northern Journal of Medical Science, vol. iv, 1844) observed sudamina in only 12 out of 220 cases examined.

The case I have detailed at some length, goes to show that miliaria is neither a symptomatic disorder, nor has any relation to the so-called sudamina arising in the progress of certain fevers (generally about the second week); but is a disease sui generis, and, like other exanthematous affections, depends upon some specific poison. Whether such poison is derived from external sources, or is generated in the blood or chylopoietic viscera, is immaterial. It should, in my humble opinion, take the same place in our nosology orginally given to it by Mason Good, Rayer, and some of the older physicians; and not be classed among the non-febrile group, Vesiculæ, as Willan, and those who have copied him, have done.

I have associated this disease, in some measure, with scarlatina, though it occurred two months afterwards, and may possibly have nothing whatever to do with it. A miliary eruption, however, resulting doubtless, in some instances, from the intense capillary congestion of the skin, has been noticed by almost every writer of any repute, as one of the most common complications of this disease.* There are certain resemblances between these two affections which it may not be uninteresting to notice.

causes, fever was almost necessarily induced, with the most profuse sweats, oppression, anxiety, and fainting; and these again were aggravated by spicy caudles, spirits, opiates, and ammoniacal medicines." (See Bateman's Synopsis of Cutaneous Diseases. London: 1829. White, Ch., Treatise on the Management of Pregnant and Lying-in Women, 8vo. I.ondnn : 1 1775.)

* The frequent occurrence of miliaria during the progress of scarlatina has been especially mentioned by Good, Rush, Withering, frequent complication. Sauvages, indeed, wished, on account of this of scarlatina variolodes. 
1. The precursory and attendant symptoms, one day's duration; the eruption appearing in both on the second day.

2. Their coequal duration in point of time, from three to eight or nine days.

3. Exfoliation of the epidermis in laminæ, whilst it is only furfuraceous in most other diseases of skin, including the exanthemata. Scarlatina is, however, highly contagious, and generally occurs only once in the same individual. In reply, it may be said, that miliary fever has prevailed epidemically in France and elsewhere several times during the seventeenth century, and must to a certain degree have been contagious; and there are many exceptions to the generally received notion that scarlatina only attacks a person once during his lifetime. The late Dr. A. Todd Thomson attended a case in which it had occurred three times.

In studying the history of miliary fever, we are struck with its extreme frequency during the middle and close of the last century, especially in France, as is shown by the profusion of articles in the different journals, as well as separate and distinct monographs, all treating of this disease, whilst we now hardly ever see it mentioned. Duvergie, for instance, in his otherwise full and elaborate work on Cutaneous Dis. eases, does not even allude to it, unless he wishes us to believe that it is a variety of acne, and synonymous with what he describes as acne miliaria. Wilson and other writers in this country likewise seem to regard it as a complaint of trifling importance, and merely make the most casual allusion to it. It is possible that the true miliary fever is less common now than formerly. My own convictions, however, are, that the disease has been overlooked in many instances, either from the eruption appearing on the thorax and other parts of the body usually concealed by the dress, or from its usually mild character, it has not had that attention paid to it which it deserves.

SPECIFICS FOR KIDNEY-DISEASE. "In this, as in other forms of Bright's disease," says Dr. Bence Jones, "no specific can be of benefit. Filling every texture, in addition to the altered texture of the kidney, with more alkali or with less alkali, or with oil, or with salt of any kind, will not remove the thickening."

Examining the Fundus Ocdur. Dr. Roseburgh of Toronto finds that the fundus of the eye can be examined without the mirror of the ophthalmcscope as follows. The lamp is placed on a table in a darkened room. The patient is seated on a chair two or three feet from the table, and facing the light. The chair of the observer is placed with the back against the table and between the patient and the lamp. When the surgeon is seated, the lamp should be immediately behind the right shoulder and very nearly on a level with the eye. By now bringing the right oye in a line with the lamp and the eye of the patient, but so as not to shade it, if the pupil had been previously dilated with atropine-the fundus is seen to be illuminated. In order to see the details of the posterior internal surface of the eye, a lens of about two inches focus is placed within an inch or two inches of the eye under examination. An inverted image of the fundus can now be seen forming an aërial image about two inches in front of the lens. The optic nerve entrance and the radiations of the retinal vessels can be seen by directing the patient to look at the light or two or three inches farther from the surgeon's eye, but in the same horizontal line. (Canada Med. Journal.)

\section{Trankactions of 通xanches.}

SHROPSHIRE SCIENTIFIC BRANCH.

ON THE SENSE OF SMELL APPLIED TO MEDICINE.

By Henry Johnson, M.D., Shrewsbury.

[Read November $8 r d, 1865$.]

THe subject of this communication will, perhaps, raise a smile; but I hope to show that it does notw deserve to be ridiculed. It is remarkable that, whils the sense of touch, of sight, and of hearing have al $A$. been very properly enlisted in the cause of practical. medicine, yet that of smell has hitherto been enis tirely neglected or little used.

I cannot help thinking, however-and the thoughfor has long occupied my mind at intervals-that of proper cultivation or education of this sense would often, if attended to, give very valuable and prac $\vec{\omega}$ tical diagnostic signs. Reading lately Sir John Fife's Manual of the Turkish Bath has again drawm my attention to the subject. In this work there are some facts quoted from Mr. D. Urquhart stronglp bearing upon this subject, and confirming the opinion which I had formed from other grounds of the prac $\vec{p}$ tical use which may be derived from educating oub sense of smell, and applying the knowledge so ac? quired to diagnosis.

Mr. Urquhart states that there is an odour pero ceived to arise from human bodies, whilst perspiring in the bath, which is characteristic of health; anf another which is perceived in disease ; and that even the kind of disorder, in some cases, may be detecte by the smell. He employed a sharp lad to deteco the peculiar odour exhaled by different persons under the use of the bath, and asserts that this individuas could discover not only the kind of disease, but even

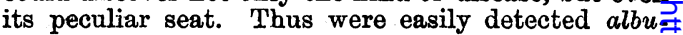
minuria, gout, rheumatism, herpes, and ague.

Mr. Urquhart says that the healthy body is not inodorous. It is endowed with a sweet odour, de scribed by those whose organs are sensitive enough to detect it " as resembling fresh sawn fir-boards." "At the common temperature, the body may be in odorous in all its parts, and the breath also; and yet, on going into a temperature of $220^{\circ} \mathrm{Fahr}$., in five minutes a slight smell of gout will come out os the feet and the breath. Half an hour later, and after being in at the higher heat ten minutes of more, the smell of gout may become very strong in the feet, legs, thighs, breast, stomach, breath, and back. The smell of herpes may have come out ino the bands, the arms, and shoulders. Half an hours. later, and after having been twice under the greatu heat, the smell may have been taken out everd where." (Pp. 334-5.)

He says, again, that in these experiments he should be wholly at sea, without the sense of smell to guids him.

Now, the results of these experiments are cer tainly very curious. And, although it must be allowed that those who do not make the Turkish batho their special study (as was done by Mr. Urquhart can little expect to arrive at such a facility in disp covering disease in this manner, yet these facts an $\$$ experiments show that many diseases are marked by 8 characteristic odour. But, without the aid of a high temperature to bring out any natural or unnaturat odour, I am convinced that valuable diagnostic signs or at any rate important indications of morbid states may often be obtained through the sense of smell. 